\title{
Distinct pattern of oxidative DNA damage and DNA repair in follicular thyroid tumours
}

\author{
Stefan Karger, Kerstin Krause, Cornelia Engelhardt, Carl Weidinger, Oliver Gimm ${ }^{1}$, \\ Henning Dralle ${ }^{1}$, Sien-Yi Sheu-Grabellus ${ }^{2}$, Kurt Werner Schmid ${ }^{2}$ and Dagmar Fuhrer ${ }^{3}$ \\ Clinic of Endocrinology and Nephrology, Department of Internal Medicine, Neurology and Dermatology, University of Leipzig, Liebigstraße 18, 04103 Leipzig, Germany \\ ${ }^{1}$ Department of General, Visceral, and Vascular Surgery, Martin Luther University of Halle-Wittenberg, Ernst-Grube-Straße 40, 06120 Halle, Saale, Germany \\ ${ }^{2}$ Institute of Pathology and Neuropathology and ${ }^{3}$ Clinic of Endocrinology and Metabolic Disorders, University of Duisburg-Essen, Hufelandstraße 55, \\ D-45147 Essen, Germany \\ (Correspondence should be addressed to D Fuhrer; Email: dagmar.fuehrer@uk-essen.de)
}

\begin{abstract}
Increased oxidative stress has been linked to thyroid carcinogenesis. In this paper, we investigate whether oxidative DNA damage and DNA repair differ in follicular adenoma (FA) and follicular thyroid carcinoma (FTC). 7,8-Dihydro-8oxoguanine (8-OxoG) formation was analysed by immunohistochemistry in 46 FAs, 52 FTCs and 18 normal thyroid tissues (NTs). mRNA expression of DNA repair genes OGG1, Mut Y homologue (MUTYH) and endonuclease III (NTHL1) was analysed by real-time PCR in 19 FAs, 25 FTCs and 19 NTs. Induction and repair of oxidative DNA damage were studied in rat FRTL-5 cells after u.v. irradiation. Moreover, activation of DNA damage checkpoints (ataxia telangiectasia mutated (ATM) and H2A histone family, member X (H2AFX (H2AFX))) and proliferation index (MIB-1) were quantified in 28 non-oxyphilic and 24 oxyphilic FTCs. Increased nuclear and cytosolic 8-OxoG formation was detected in FTC compared with follicular adenoma, whereby cytosolic 8-OxoG formation was found to reflect RNA oxidation. Significant downregulation of DNA repair enzymes was detected in FTC compared with FA. In vitro experiments mirrored the findings in FTC with oxidative stress-induced DNA checkpoint activation and downregulation of OGG1, MUTYH and NTHL1 in FRTL-5 cells, an effect that, however, was reversible after $24 \mathrm{~h}$. Further analysis of FTC variants showed decreased oxidative DNA damage, sustained checkpoint activation and decreased proliferation in oxyphilic vs nonoxyphilic FTC. Our data suggest a pathophysiological scenario of accumulating unrepaired DNA/RNA damage in FTC vs counterbalanced DNA/RNA damage and repair in FA. Furthermore, this study provides the first evidence for differences in oxidative stress defence in FTC variants with possible implications for therapeutic response and prognostic outcome.
\end{abstract}

Journal of Molecular Endocrinology (2012) 48, 193-202

\section{Introduction}

The thyroid follicular cell is at increased risk of oxidative stress resulting in oxidative DNA damage induced by reactive oxidative species (ROS). In particular, an imbalance between pro- and antioxidative factors has been suggested as an important mechanism in thyroid tumourigenesis (Krohn et al. 2005, Song et al. 2007). In thyrocytes, $\mathrm{H}_{2} \mathrm{O}_{2}$ is generated by thyroid oxidases in response to thyrotropin and acts as an essential cofactor for thyroid peroxidase during thyroid hormone synthesis (De Deken et al. 2002, Song et al. 2010). Excess of $\mathrm{H}_{2} \mathrm{O}_{2}$ is eliminated by the antioxidative system, e.g. superoxide dismutase, glutathione peroxidases and peroxiredoxins (Köhrle et al. 2005, Song et al. 2007). Using a rodent model, Maier et al. (2006) have recently demonstrated that, in contrast to other organs, normal thyroid tissue (NT) exhibits an eight to ten times higher rate of spontaneous mutations. Furthermore, in a very recent study, Driessens et al. (2009) have shown that $\mathrm{H}_{2} \mathrm{O}_{2}$ causes single- and double-strand DNA breaks in thyroid cells. This in vitro evidence of a particularly mutagenic environment of the thyroid is in good agreement with the clinical picture of nodular thyroid disease: i) the very high prevalence of nodular thyroid lesions in up to $50 \%$ of the adult population, of which a substantial portion is clonal (Volzke et al. 2003, Krohn et al. 2005), ii) the frequent finding of incidental papillary microcarcinoma, which arises from somatic mutations in the RAS-BRAF-MAPK cascade in operated thyroids (Carlini et al. 2005, Shattuck et al. 2005, Kondo et al. 2006) and iii) the increasing prevalence of thyroid cancer with age, with a peak in the sixth and seventh decade of life in women and men respectively (Liu et al. 2001, Husmann et al. 2010, Dal Maso et al. 2011).

ROS-induced DNA damage involves single- or double-strand DNA breaks, purine and pyrimidine or deoxyribose modifications as well as DNA cross links (Hoeijmakers 2009, Jackson \& Bartek 2009, van Loon et al. 2010). The most widely studied DNA oxidation product is 7,8-dihydro-8-oxoguanine (8-OxoG), 
a highly mutagenic product of the interaction of ROS and DNA (Beckmann \& Ames 1997, Jackson \& Bartek 2009, van Loon et al. 2010). If unrepaired, the base lesion promotes a $\mathrm{G} \rightarrow \mathrm{C}$ to $\mathrm{T} \rightarrow \mathrm{A}$ transversion following replication (Kreutzer \& Essigmann 1998). Detection and repair of oxidative DNA damage are conducted by the base excision repair (BER) system (Klungland et al. 1999, Minowa et al. 2000, David et al. 2007, Russo et al. 2007). In eukaryotes, in particular, the 8-OxoG DNA glycosylase 1 (OGG1) plays a prominent role in recognition and excision of 8-OxoG sites (Rosenquist et al. 1997). In addition, Mut Y homologue (MUTYH) and endonuclease III (NTHL1) are encoding BER enzymes responsible for repair of oxidative purine and pyrimidine DNA base lesions respectively (Al-Tassan et al. 2002, Russo et al. 2007).

So far, no systematic study has been performed to assess the extent of oxidative DNA damage in thyroid tumours. In this paper, we explore the hypothesis that increased oxidative DNA damage may be present with ongoing thyroid transformation leading to genomic instability and dedifferentiation. In this paper, we studied the extent of 8-OxoG formation and oxidative DNA damage repair in follicular adenomas (FAs) and follicular thyroid carcinomas (FTCs) in order to get further information on whether follicular thyroid tumours evolve in a sequential (adenoma-carcinoma sequence) or distinct way. Furthermore, we applied an in vitro model of the oxidative stress response to compare the physiological response with the in vivo situation we observed in follicular thyroid tumours. We found that i) the formation of 8-OxoG DNA adducts is increased in FTC and FA compared with NT, ii) this is coincidenced by the decreased gene expression of BER enzymes in FTC and iii) the induction of the DNA damage response in FTC is downregulated compared with FA. In addition, we found discrepancies in the extent of DNA damage in oxyphilic FTC compared with non-oxyphilic FTC variants.

\section{Materials and methods}

\section{Thyroid samples}

Thyroid samples were obtained from patients undergoing thyroid surgery for nodular thyroid disease or thyroid cancer. Thyroid specimens were obtained from the Department of Surgery, Martin-Luther-University Hospital, Halle, and from the Department of Pathology and Neuropathology, University of Duisburg-Essen, Essen, Germany.

Duplicates of 19 hypofunctional FAs, 19 corresponding NTs from the same patient and 25 FTCs were studied for mRNA expression of hOGG1, hMUTYH and $h N T H L 1$. For immunohistochemical analysis of 8-OxoG formation, DNA damage response (ataxia telangiectasia mutated (ATM) and H2A histone family, member X (H2AFX) and proliferation (Ki-67 protein expression), paraffin-embedded tissue sections from 46 FAs, 52 FTCs (comprising 28 non-oxyphilic and 24 oxyphilic) and 18 NTs were studied.

For exclusion of an age-related influence of oxidative stress on our data, FTC and FA patients were age matched. The median age of FTC patients was 55 (mean $51 \cdot 08 \pm 16 \cdot 29)$ years and of FA patients 52 (mean $52 \cdot 39 \pm 15 \cdot 15)$ years.

Classification of the thyroid nodules was performed by the pathologists according to World Health Organization (WHO) criteria. The term follicular adenoma was applied for benign follicular lesions, which were completely encapsulated. The term follicular carcinoma was used if capsule invasion and/or vascular invasion were present. The term oxyphilic tumour (syn. oncocytic, Hürthle cell tumour) was applied in case of a tumour with abundant granular eosinophilic cytoplasm, as a consequence of increased mitochondrial content (Vonate et al. 2002, Porcelli et al. 2010). All patients gave informed consent and the study was approved by the local ethics committee.

\section{Cell culture}

Follicular rat thyroid (FRTL-5) cells (kindly provided by Prof. Di Lauro, Naples) were split into 6-well plates $\left(3 \times 10^{5}\right.$ cells/well $)$ and were cultured in a 2:1:1 mixture of DMEM:Ham's F12:MCDB104 supplemented with $5 \%$ newborn calf serum (all from Gibco BRL, Life Technologies), $10 \mathrm{mg} / \mathrm{ml}$ insulin, $0.4 \mathrm{mg} / \mathrm{ml}$ hydrocortisone (Calbiochem, San Diego, CA, USA), $45 \mathrm{mg} / \mathrm{ml}$ ascorbic acid (Sigma), $5 \mathrm{mg} / \mathrm{ml}$ transferrin (Calbiochem) and $5 \mathrm{mU} / \mathrm{ml}$ bovine TSH (Sigma) until $70 \%$ confluence. Cells were exposed to a single dose of u.v. irradiation $\left(0 \cdot 001 \mathrm{~J} / \mathrm{cm}^{2}\right)$ at room temperature. Four, 8 and $24 \mathrm{~h}$ after u.v. irradiation, FRTL-5 cells were washed twice with PBS and were shock frozen in liquid nitrogen and stored at $-80^{\circ} \mathrm{C}$. Controls were treated identically except for u.v. irradiation. The experiment was performed in triplicates.

\section{RNA extraction and real-time RT-PCR}

RNA was isolated from snap-frozen thyroid tissue and FRTL-5 cells using TRIzol reagent (Invitrogen). One microgram of RNA per sample was reverse transcribed in a final mixture of $5 \times$ first-strand buffer (250 mM Tris- $\mathrm{HCl}$ (pH 8.3), $375 \mathrm{mM} \mathrm{KCl}, 15 \mathrm{mM}$ $\mathrm{MgCl}_{2}$ (Gibco BRL), $0.5 \mathrm{mM}$ dNTPs, $5 \mathrm{mM}$ dithiothreitol (Gibco BRL), 15 U Prime RNAse inhibitor (PeqLab, Erlangen, Germany), 0.5 mg random hexamer primers and $200 \mathrm{U}$ Moloney murine leukaemia virus reverse 
transcriptase (Gibco BRL). Reverse transcription was performed at $37^{\circ} \mathrm{C}$ for $60 \mathrm{~min}$ and $94^{\circ} \mathrm{C}$ for $5 \mathrm{~min}$. Quantitative real-time PCR using exon spanning primer for human and rat OGG1, MUTYH and NTHL1 was performed using the LightCycler System and LightCycler-DNA Master SYBR Green I kit (Roche) according to the manufacturer's instructions. Annealing temperatures and $\mathrm{MgCl}_{2}$ concentrations were optimised to create a one-peak melting curve. Primers and PCR conditions were as follows:

Primer sequences for human tissue:

OGG1 Forward: 5'-GAA ATT CCA AGG TGT GCG AC-3' Reverse: 5'-CCA TTG ACA TCA TCA AGC TG-3' MUTYH Forward: $5^{\prime}$-GAG GAG TGT GCT CCC AAC AC-3' Reverse: 5'-AGG CTG TTC CAG AAC ACA GG-3' NTHL1 Forward: 5'-CGG AAA GCA CAG AGA CTG C-3' Reverse: 5'-TGG AGA GCA TCA GTG ACA GC-3'

PCR conditions:

After initial denaturation (30 s) at $95^{\circ} \mathrm{C}$, PCR was carried out for 40 cycles: for $O G G 1,95^{\circ} \mathrm{C}$ for $0 \mathrm{~s}, 72^{\circ} \mathrm{C}$ for $7 \mathrm{~s}$ and $59{ }^{\circ} \mathrm{C}$ for $8 \mathrm{~s}, 4 \mathrm{mM} \mathrm{MgCl}_{2}$; for $\mathrm{MUTYH}, 95^{\circ} \mathrm{C}$ for $0 \mathrm{~s}, 72{ }^{\circ} \mathrm{C}$ for $7 \mathrm{~s}$ and $60{ }^{\circ} \mathrm{C}$ for $8 \mathrm{~s}, 4 \mathrm{mM} \mathrm{MgCl}{ }_{2}$; and for NTHL1, $95^{\circ} \mathrm{C}$ for $0 \mathrm{~s}, 72^{\circ} \mathrm{C}$ for $7 \mathrm{~s}$ and $60^{\circ} \mathrm{C}$ for $11 \mathrm{~s}$, $3 \mathrm{mM} \mathrm{MgCl} 2$. The LightCycler Software calculated the threshold cycles.

Primer sequences for rat FRTL-5 cells:

\begin{tabular}{|c|c|}
\hline & Forward: 5'-CAG CTC TAT AGC CAC TGG GC-3' \\
\hline & \\
\hline & ard: 5'-CAA CCA CA \\
\hline & $\begin{array}{l}\text { Forward: 5'-GTG CAC GTT GAG CAA GTG AT-3' } \\
\text { Reverse: 5'-CAC TTT GAG GGG TTC AGC AT-3' }\end{array}$ \\
\hline
\end{tabular}

\section{PCR conditions:}

After initial denaturation $(30 \mathrm{~s})$ at $95^{\circ} \mathrm{C}$, PCR was carried out for 40 cycles: for $\operatorname{Ogg} 1,95^{\circ} \mathrm{C}$ for $0 \mathrm{~s}, 72^{\circ} \mathrm{C}$ for $7 \mathrm{~s}$ and $62{ }^{\circ} \mathrm{C}$ for $12 \mathrm{~s}, 3 \mathrm{mM} \mathrm{MgCl} 2$; for $M y h, 95{ }^{\circ} \mathrm{C}$ for $0 \mathrm{~s}, 72^{\circ} \mathrm{C}$ for $7 \mathrm{~s}$ and $58^{\circ} \mathrm{C}$ for $12 \mathrm{~s}, 3 \mathrm{mM} \mathrm{MgCl}$; and for $N$ th, $95{ }^{\circ} \mathrm{C}$ for $0 \mathrm{~s}, 72^{\circ} \mathrm{C}$ for $7 \mathrm{~s}$ and $62^{\circ} \mathrm{C}$ for $13 \mathrm{~s}$, $3 \mathrm{mM} \mathrm{MgCl}{ }_{2}$. The LightCycler Software calculated the threshold cycles.

The mRNA expression of the housekeeping protein $\beta$-actin and ribosomal rS6 protein was used for normalisation of mRNA expression in human samples and FRTL-5 cells respectively. To quantify changes in mRNA expression patterns, real-time PCR was performed using the LightCycler DNA Master SYBR Green I kit (Roche) as described previously (Krause et al. 2008, Karger et al. 2009). In the thyroid tissues, the fold difference $(n)$ in up- or downregulation of mRNA expression was calculated based on Pfaffl's methodology (Pfaffl 2001) as follows:

$n=\frac{2^{\text {(threshold cycle of NT }- \text { threshold cycle of diseased tissues (DT)) }}}{2^{\text {(tc ACTB (NT) }- \text { tc ACTB (DT)) }}}$.

'Diseased tissue' (DT) corresponds to FA, and FTC, whereas 'normal tissue' corresponds to the surrounding tissue of FA. In the FRTL-5 cells, fold difference $(n)$ in up- or downregulation of mRNA expression was calculated (Pfaffl 2001) as follows:

$n=\frac{2^{\text {(threshold cycle of control cells }- \text { threshold cycle of u.v.-treated cells) }}}{2^{\text {(tc rS6 (control) }- \text { tc rS6 (u.v.-treated cells) })}}$.

The Mann-Whitney $U$ test within the SPSS 11.5 Software (SPSS Inc Chicago, IL, USA) was applied to calculate the statistical significance of differences in the mRNA expression of the respective genes between thyroid tissues.

\section{Western blot analysis}

Western blot analysis was performed using antibodies against H2AFX (Cell Signaling, Charlottesville, VA, USA) and the S139-phosphorylated form of H2AFX $(\gamma$ H2AFX; S139-H2AFX; Upstate Biotechnology, Lake Placid, NY, USA). Cells were lysed in buffer containing $10 \mathrm{mM}$ Tris, $400 \mathrm{mM} \mathrm{NaCl}, 1 \mathrm{mM}$ EDTA and $0 \cdot 1 \% \mathrm{NP}-$ 40 (all from Sigma). Fifty micrograms of protein were separated on $14 \%$ SDS gels followed by semi-dry western blotting. Subsequently, membranes were blocked with $5 \%$ BSA in TBST $(50 \mathrm{mM}$ Tris- $\mathrm{HCl}(\mathrm{pH}$ 7.5 ) and $150 \mathrm{mM} \mathrm{NaCl}$ containing $0.05 \%$ Tween-20). Blots were probed overnight with the following dilutions of antibodies in TBST containing 5\% BSA: anti-H2AFX (1:1000), anti-p-S139-H2AFX ( $\gamma$ H2AFX; $1: 1000)$ and anti- $\beta$-actin (1:500). After incubation with a secondary anti-rabbit antibody coupled to HRP (Cell Signaling), immunocomplexes were visualised by enhanced chemiluminescence (Pierce, Rockford, IL, USA). $\beta$-Actin was used as a loading control.

\section{Immunohistochemistry}

Paraffin-embedded tissue sections ( $2 \mu \mathrm{m})$ were incubated with one of the following antibodies: anti-8-OHdG/ 8-OHG, 1:500 (Rockland, Gilbertsville, PA, USA); antiphospho-S1981-ATM, 1:200 (Abcam); anti-phosphoS139-H2AFX, 1:200 (Cell Signaling) as well as anti-Ki-67 (MIB-1) antibody, 1:100 (DAKO, Glostrup, Denmark) using previously described immunohistochemistry protocols (Krause et al. 2007, Karger et al. 2009).

For RNA elimination before incubation with the anti8-OHdG/8-OHG antibody, tissue sections were 
pretreated with $7000 \mathrm{U} / \mathrm{ml}$ RNAse A (Qiagen Sciences) for $12 \mathrm{~h}$ at $37^{\circ} \mathrm{C}$.

Immunoreactivity was demonstrated using a biotinylated secondary anti-rabbit antibody, streptavidin peroxidase and diaminobenzidine. Sections were counterstained with hemalaun and mounted in Aquatex (Merck).

$\mathrm{H}_{2} \mathrm{O}_{2}$ pretreated NT sections (for 8-OxoG staining) and tissue sections from small intestine and colon cancer (for p-ATM, $\gamma$ H2AFX and MIB-1 staining) were used as positive controls.

Triplicates per tissue sample were investigated, i.e. three sequential sections. The overall amount of nuclear and cytosolic 8-OxoG immunoreactivity in thyrocytes was determined in ten randomly selected sections at $200 \times$ magnification per slide. Subsequently, the mean \pm s.D. and the median of the percentage of positively stained nuclei and cytoplasm/thyrocytes were calculated for FA, FTC and separately for the FTC subtypes. The nuclear and cytosolic 8-OxoG immunoreactivity was categorised according to Bartkova et al. (2005): i) negative (no positive staining or up to $1 \%$ of positive cells), ii) low (with at least $20 \%$ of the section showing $2-35 \%$ positive cells), iii) moderate (with at least $20 \%$ of the section showing $36-75 \%$ positive cells) and iv) strong (with at least $20 \%$ of the section showing $76-100 \%$ positive cells). Determination of the index of proliferation (positive nuclear Ki-67/MIB-1 labelling) was performed by counting 500 tumour cells in the most intense staining areas with $400 \times$ magnification and was quantified as percentage. The Mann-Whitney $U$ test within the SPSS 11.5 Software was applied to calculate the statistical significance of differences in protein expression.

\section{Results}

\section{FTC shows accumulation of unrepaired DNA adducts with increased formation of 8-OxoG adducts}

To study the extent of oxidative DNA damage in follicular thyroid tumours, we used a monoclonal antibody, which detects $8-\mathrm{OHdG} / 8-\mathrm{OHG}$ oxidation products induced by ROS. Significantly increased nuclear and cytosolic 8-OxoG immunoreactivity was found in FTCs and FAs compared with NTs (Fig. 1A). The mean nuclear 8 -OxoG staining was $64 \cdot 2 \pm 29 \cdot 1 \%$ in FA (median $70 \%$ ) and $64 \cdot 7 \pm 33 \cdot 1 \%$ in FTC (median $85 \%$, not significant). According to the modified scoring model of Bartkova et al. (2005), $47 \cdot 6 \%$ of FAs showed a strong nuclear 8 -OxoG staining vs $55 \cdot 3 \%$ of FTCs (strong=at least $20 \%$ of the section showing $76-100 \%$ nuclei with 8 -OxoG immunoreactivity). On the subcellular level, 8-OxoG staining was more pronounced in the cytosol than in the nucleus both in FTC and in FA. Thus, the mean cytosolic 8-OxoG staining in FA was $70 \cdot 6 \pm 28 \cdot 2 \%$ (median $85 \%$ ) and in FTC $81 \cdot 5 \pm 27 \cdot 8 \%$ (median $100 \%$; Fig. 1B). This difference was significant at $P<0 \cdot 02$. According to the modified scoring model of Bartkova et al. (2005), 57.1\% of FAs showed a strong overall cytosolic 8-OxoG staining vs $72.3 \%$ of FTCs. The results of the scoring analysis of nuclear and cytosolic 8-OxoG staining in FA and FTC are shown in Supplementary Figure 1, see section on supplementary data given at the end of this article. No correlation was found between the amount/strength of nuclear and cytosolic 8-OxoG expression and the respective FTC tumour stages (Table 1).

Recent studies indicate that RNA, such as mRNA and rRNA, is very vulnerable to oxidative damage (Kong \& Lin 2010). To clarify whether cytosolic 8-OxoG formation in FTC and FA corresponds to oxidative mitochondrial DNA or mRNA/rRNA damage, we subjected tissue samples to RNAse treatment before 8-OxoG staining. We observed a marked decrease in cytosolic 8-OxoG immunoreactivity, which suggests that this cytosolic 8-OxoG staining reflects oxidative mRNA/rRNA damage (Fig. 2).
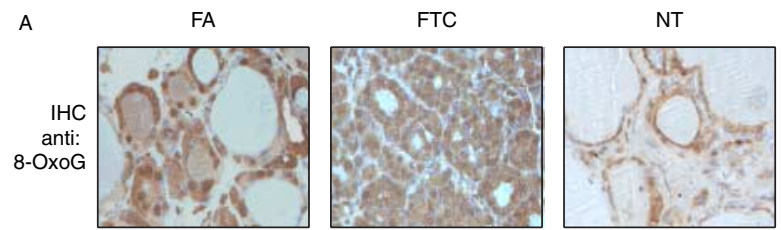

8-OHdG/8-OHG
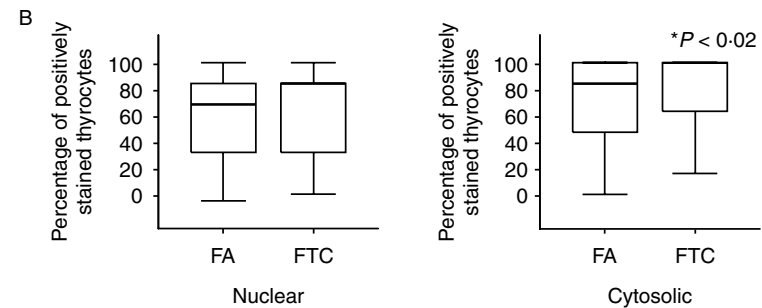

Figure 1 (A) Representative images of 8-OxoG immunohistochemistry in benign and malignant thyroid follicular tumours and normal thyroid tissue: FTC displays higher median nuclear 8-OxoG staining and significantly higher median cytosolic 8-OxoG staining than FA. Nuclear and cytosolic 8-OxoG accumulation is much lower in NT. Magnification: $400 \times$. (B) Box plots show median and distribution (box area $=50 \%$ of samples) of the percentage of 8-OxoG positively stained thyrocytes (nuclear and cytosolic) in FA and FTC. The mean overall amount of nuclear 8-OxoG staining was $64.2 \pm 29.1 \%$ in FA (median $70 \%$ ) and $64.7 \pm 33.1 \%$ in FTC (median $85 \%$ ). The mean overall amount of cytosolic $8-O x o$ G staining in FA was $70 \cdot 6 \pm 28 \cdot 2 \%$ (median $85 \%$ ) and in FTC $81 \cdot 5 \pm 27 \cdot 8 \%$ (median $100 \%$; $B$ ). This difference was calculated as significant $\left({ }^{*} P<0.02\right.$; Mann-Whitney $U$ test). FA, follicular adenoma; FTC, follicular carcinoma; NT, normal thyroid tissue. Full colour version of this figure available via http:// dx.doi.org/10.1530/JME-11-0119. 


\section{DNA damage repair genes are downregulated in FTCs}

As detection and repair of oxidative DNA damage are conducted by the BER system, we studied the gene

Table 1 Correlation of histological subtype, patient's gender, age and Tumour Node metastasis (TNM) staging with nuclear and cytosolic 8-OxoG expression of $n=47$ follicular thyroid carcinomas investigated in the study

\begin{tabular}{|c|c|c|c|c|c|c|}
\hline No. $^{a}$ & HS & Year $^{\mathrm{b}}$ & $\begin{array}{l}\text { Age, } \\
\text { gender }\end{array}$ & TNM & $\begin{array}{l}\text { 8-0xo } \\
\text { nuclear }\end{array}$ & $\begin{array}{l}\text { 8-Oxo } \\
\text { cytosolic }\end{array}$ \\
\hline 1 & NOF & 1999 & $29, M$ & рT3 Nx Mx & 85 & 100 \\
\hline 2 & NOF & 1999 & $26, \mathrm{~F}$ & p2T Nx Mx & 35 & 35 \\
\hline 3 & OF & 1999 & $62, M$ & p2T Nx Mx & 10 & 10 \\
\hline 4 & NOF & 1999 & $23, F$ & p2T Nx Mx & 85 & 100 \\
\hline 5 & NOF & 2000 & $41, \mathrm{~F}$ & р2T Nx Mx & 85 & 100 \\
\hline 6 & NOF & 2000 & $57, \mathrm{~F}$ & p2T Nx Mx & 100 & 100 \\
\hline 7 & NOF & 2000 & $36, F$ & p2T Nx Mx & 100 & 100 \\
\hline 8 & OF & 2000 & $65, F$ & р2T Nx Mx & 85 & 100 \\
\hline 9 & OF & 2000 & $43, \mathrm{~F}$ & p2T Nx Mx & 20 & 20 \\
\hline 10 & NOF & 2000 & $31, \mathrm{~F}$ & p2T $\mathrm{Nx} M x$ & 100 & 100 \\
\hline 11 & OF & 2000 & $59, \mathrm{~F}$ & p2T Nx Mx & - & - \\
\hline 12 & OF & 2000 & $24, \mathrm{M}$ & p2T Nx Mx & 20 & 10 \\
\hline 13 & OF & 2000 & $70, \mathrm{~F}$ & p2T Nx Mx & 20 & 100 \\
\hline 14 & NOF & 2000 & $61, F$ & p2T Nx Mx & 85 & 85 \\
\hline 15 & NOF & 2000 & $35, \mathrm{M}$ & p2T Nx Mx & 100 & 65 \\
\hline 16 & OF & 2000 & $48, M$ & р3Т Nx Mx & 85 & 100 \\
\hline 17 & NOF & 2000 & $61, \mathrm{~F}$ & p2T Nx Mx & - & - \\
\hline 18 & NOF & 2000 & $77, \mathrm{M}$ & p2T Nx Mx & 85 & 65 \\
\hline 19 & NOF & 2000 & $31, \mathrm{~F}$ & p2T Nx Mx & - & - \\
\hline 20 & NOF & 2001 & $64, \mathrm{M}$ & р2T Nx Mx & 100 & 100 \\
\hline 21 & NOF & 2005 & $61, \mathrm{~F}$ & p2T Nx Mx & 100 & 100 \\
\hline 22 & OF & 2005 & $61, F$ & р2T Nx Mx & 85 & 100 \\
\hline 23 & OF & 2005 & $73, \mathrm{~F}$ & р2T Nx Mx & 35 & 100 \\
\hline 24 & NOF & 2005 & $61, \mathrm{~F}$ & p2T Nx Mx & 100 & 85 \\
\hline 25 & NOF & 2005 & $50, \mathrm{~F}$ & p2T Nx Mx & 85 & 100 \\
\hline 26 & OF & 2005 & $19, \mathrm{~F}$ & р2T Nx Mx & 65 & 65 \\
\hline 27 & OF & 2005 & $51, \mathrm{~F}$ & p2T Nx Mx & 35 & 35 \\
\hline 28 & OF & 2005 & $69, \mathrm{~F}$ & р2T $N x M x$ & 100 & 100 \\
\hline 29 & OF & 2005 & $83, \mathrm{~F}$ & p2T Nx Mx & 85 & 100 \\
\hline 30 & NOF & 2005 & $59, \mathrm{~F}$ & p4T NO Mx & 100 & 100 \\
\hline 31 & NOF & 2005 & $38, F$ & р2T Nx Mx & - & - \\
\hline 32 & NOF & 2005 & $57, \mathrm{~F}$ & р2T Nx Mx & 35 & 30 \\
\hline 33 & OF & 2005 & $83, \mathrm{~F}$ & p2T Nx Mx & 10 & 100 \\
\hline 34 & NOF & 2005 & $31, \mathrm{~F}$ & p2T Nx Mx & - & - \\
\hline 35 & OF & 2005 & $64, \mathrm{~F}$ & р2T Nx Mx & 5 & 100 \\
\hline 36 & OF & 2005 & $44, \mathrm{~F}$ & p2T Nx Mx & 10 & 65 \\
\hline 37 & NOF & 2005 & $49, \mathrm{~F}$ & p2T Nx Mx & 100 & 100 \\
\hline 38 & OF & 2005 & $49, \mathrm{~F}$ & p2T Nx Mx & 90 & 85 \\
\hline 39 & NOF & 2005 & $48, M$ & p2T Nx Mx & 5 & 100 \\
\hline 40 & OF & 2005 & $56, \mathrm{~F}$ & р2T Nx Mx & 65 & 100 \\
\hline 41 & NOF & 2005 & $49, \mathrm{M}$ & p2T Nx Mx & 85 & 100 \\
\hline 42 & NOF & 2005 & $36, \mathrm{~F}$ & p2T Nx Mx & 20 & 20 \\
\hline 43 & NOF & 2005 & $30, \mathrm{~F}$ & р2T Nx Mx & 85 & 100 \\
\hline 44 & OF & 2006 & $65, \mathrm{M}$ & p2T Nx Mx & 85 & 85 \\
\hline 45 & OF & 2006 & $72, \mathrm{M}$ & p2T Nx Mx & 35 & 100 \\
\hline 46 & OF & 2006 & $70, \mathrm{~F}$ & р2T Nx Mx & 65 & 85 \\
\hline 47 & OF & 2006 & $56, \mathrm{M}$ & p2T Nx Mx & 50 & 50 \\
\hline 48 & OF & 2006 & $33, \mathrm{~F}$ & p2T Nx Mx & 85 & 85 \\
\hline 49 & NOF & 2006 & $30, \mathrm{M}$ & р3Т Nx Mx & 65 & 100 \\
\hline 50 & NOF & 2006 & $56, \mathrm{~F}$ & p2T Nx Mx & 5 & 100 \\
\hline 51 & NOF & 2006 & $56, \mathrm{M}$ & p2T Nx Mx & 65 & 65 \\
\hline 52 & NOF-M & 2006 & $54, \mathrm{M}$ & $\mathrm{x} \times \mathrm{M} 1$ & 85 & 85 \\
\hline
\end{tabular}

${ }^{a}$ No. in tissue array; ${ }^{b}$ Year of collection; NOF, Non-oxyphilic FTC; OF, Oxyphilic FTC; HS, Histological subtype. expression of OGG1, MUTYH and NTHL1 in FTC, FA and NT. mRNA expression of the three BER genes was detected in all thyroid tissue samples. Compared with FA, FTC showed a significant downregulation of all three BER genes in FTC $(P<0.009$ for OGG1, $P<0.02$ for MUTYH and $P<0.023$ for NTHL1; Fig. 3). The comparison of FA and NT showed increased mRNA expression of all three BER genes in the follicular adenomas, but this failed to reach statistical significance (Fig. 3). Additional investigations on the correlation between the gene expression levels of OGG1, NTHL1 and MUTYH and the respective tumour stages of all FTC yielded no positive results. All data are shown in Table 2.

\section{Induction of oxidative stress in FRTL- 5 cells mirrors in vivo finding in FTC}

To study the dynamics of oxidative DNA damage and repair in thyrocytes, we used u.v. irradiation of FRTL-5 cells as an in vitro model for oxidative stress induction. U.v. irradiation of FRTL-5 cells led to a significant mRNA downregulation of all three investigated BER genes after $4-8 \mathrm{~h} \quad(P<0.025$ for $\operatorname{Ogg} 1, P<0.017$ for Muty $h$ and $P<0.025$ for NTHL1; Fig. 4A) in comparison with the non-irradiated control FRTL- 5 cells. After $24 \mathrm{~h}$, the mRNA expression of all three BER genes was restored to the level of control cells (Fig. 4A).

In addition, we investigated the activation of the DNA damage response by the phosphorylation of histone H2AFX. Upon DNA damage, activated histone H2AFX is thought to restructure chromatin and assist in the recruitment of DNA repair and signalling factors (van Attikum \& Gasser 2009). Before u.v. irradiation, we observed only faint $H 2 A F X$ expression and absence of $\gamma \mathrm{H} 2 \mathrm{AFX}$. Four and $8 \mathrm{~h}$ after irradiation, we found a strong induction of $\gamma H 2 A F X$ expression (Fig. 4B). Thereby, the kinetics of H2AFX protein activation and mRNA expression of BER genes were reciprocal.

\section{Differences in 8-OxoG formation and DNA damage response between oxyphilic and non-oxyphilic FTC variants}

While 8-OxoG formation was increased in FTC compared with FA (Fig. 1), we particularly noted differences in 8-OxoG-staining intensity depending on the histopathological subtype of FTC investigated. We thus decided to perform subgroup analysis of our FTC samples comprising oxyphilic FTC and non-oxyphilic FTC. We found that 8-OxoG staining was more pronounced in non-oxyphilic FTC vs oxyphilic FTC with significant differences in the degree of nuclear 8-OxoG formation between the two FTC variants (non-oxyphilic FTC, mean $75 \cdot 4 \pm 30 \cdot 7 \%$, median 


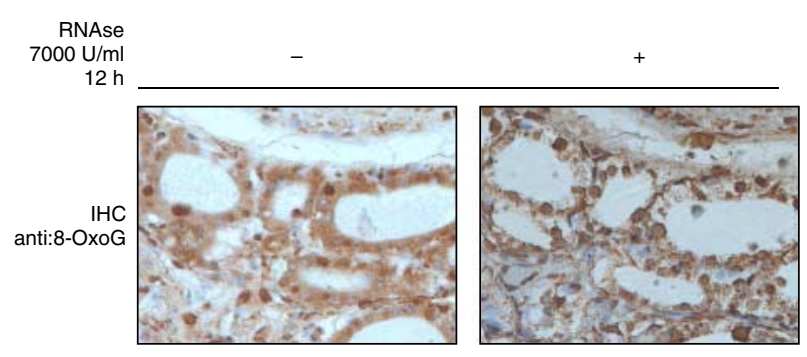

Figure 2 RNAse treatment leads to loss of cytosolic 8-OxoG staining suggesting that cytosolic staining is due to oxidative RNA damage. Representative images of cytosolic 8-OxoG immunostaining in FTC treated with $7000 \mathrm{U} / \mathrm{ml}$ RNAse for $12 \mathrm{~h}$ at $37^{\circ} \mathrm{C}$. Control slides were treated with buffer only. Magnification: $400 \times$. Full colour version of this figure available via http://dx.doi.org/10. 1530/JME-11-0119.

$85 \%$ positive nuclei vs oxyphilic FTC, mean 53.5 $\pm 31.8 \%$, median $65 \%$ positive nuclei; $P<0 \cdot 015$; Fig. 5 A and $\mathrm{B})$. Whereas the mean nuclear 8 -OxoG staining in FA $(64 \cdot 2 \pm 29 \cdot 1 \%$; median $70 \%)$ and in the whole group of FTC $(64 \cdot 7 \pm 33 \cdot 1 \%$; median $85 \%)$ was not significantly different, the comparison of 8-OxoG formation between non-oxyphilic FTC vs FA showed a clear preponderance of nuclear 8-OxoG accumulation in non-oxyphilic FTC (mean $75 \cdot 4 \pm 30 \cdot 7 \%$ (median $85 \%$ ) vs mean $64 \cdot 2 \pm 29 \cdot 1 \%$ (median $70 \%)$ ). This difference was significant at $P<0 \cdot 04$. Comparison of cytosolic 8-OxoG staining in non-oxyphilic FTC vs FA (mean $85.4 \pm 24.6 \%$ (median $100 \%$ ) vs mean 70.6 $\pm 28.2 \%$ (median $85 \%)$ ) and the whole group of FTC vs FA showed significant $(P<0.007$ and $P<0.02$ respectively) expression differences. Interestingly, non-oxyphilic FTC also exhibited a higher rate of cellular proliferation reflected by the MIB-1 index of proliferation (median $2 \cdot 1 \%$ ) compared with oxyphilic FTC (median $1 \cdot 0 \%$; Fig. 5C).

To clarify whether the differences in 8-OxoG formation in the FTC variants correlate with different degrees of activation of cell cycle checkpoint kinases, we performed immunohistochemistry using specific antibodies against the activated form of ATM (p-S1981) and H2AFX (p-S139) (Bartkova et al. 2005). Phosphorylation of these markers in response to DNA damage induces DNA repair and elicits growth arrest or apoptosis (Tanaka et al. 2007).

A moderate nuclear and low cytosolic phospho-ATM expression was detected in non-oxyphilic FTC variants, whereas a strong nuclear and cytosolic phospho-ATM expression was found in the oxyphilic tumours (Supplementary Figure 2, see section on supplementary data given at the end of this article). Furthermore, a moderate nuclear staining of $\gamma \mathrm{H} 2 \mathrm{AFX}$ was detected in both non-oxyphilic and oxyphilic FTCs. Additionally, in oxyphilic FTC, we observed a moderate cytosolic $\gamma$ H2AFX immunostaining pattern, which was completely absent in non-oxyphilic FTC (Supplementary Figure 2, see section on supplementary data given at the end of this article).

\section{Discussion}

In this paper, we follow the hypothesis that oxidative DNA damage is implicated in thyroid tumourigenesis and plays an important pathogenic role in follicular thyroid carcinogenesis. In our study, we concentrated on follicular tumours because their molecular pathogenesis is yet unresolved and it is not known whether follicular adenoma and carcinoma evolve in a sequential way. To explore our paradigm that increasing oxidative stress is relevant to carcinogenesis, we investigated a series of FAs and FTCs using 8-OxoG staining as an indicator of oxidative DNA damage. Strong 8-OxoG staining was observed in the nuclear and cytosolic compartments in FA and FTC, with a significantly higher cytosolic staining index in the FTC compared with FA. Further studies suggested that cytosolic 8-OxoG staining in the tumours may reflect oxidative RNA modifications.

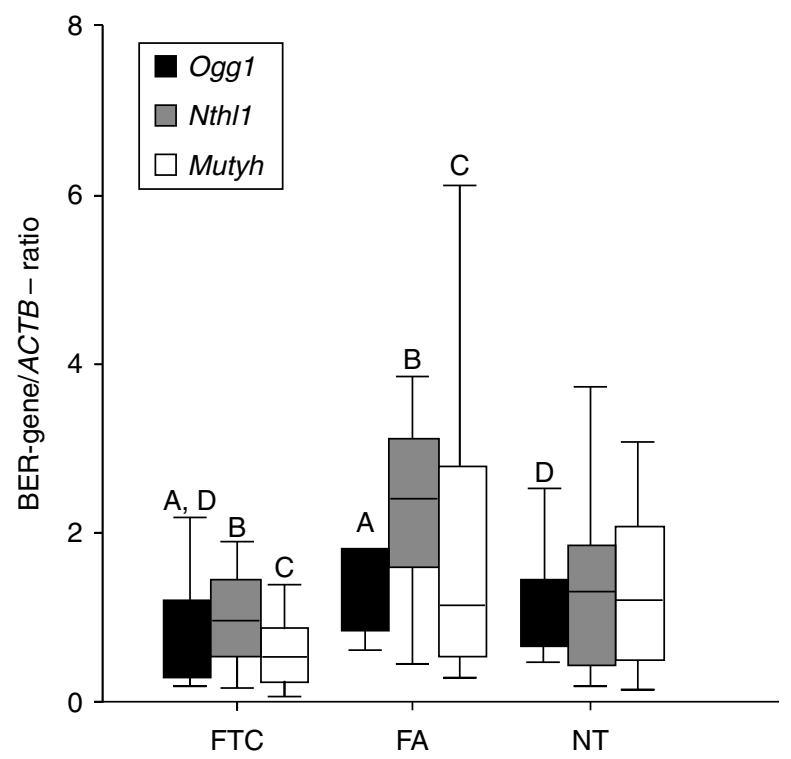

Figure 3 mRNA expression of the DNA base excision repair enzymes Ogg1, Nthl1 and Mutyh in normal thyroid tissues (NTs), follicular adenoma (FA) and follicular thyroid carcinoma (FTC). Gene expression was normalised for ACTB expression and determined by real-time PCR as described in the Materials and methods section. Box plots show median and distribution (box area $=50 \%$ of samples) of OGG1, NTHL1 and MUTYH mRNA expression in the explored thyroid tissues, which allowed statistically significant separation: $P<0.009$ (A), $P<0.02$ (B), $P<0.023$ (C) and $P<0.04$ (D; Mann-Whitney $U$ test). (A) OGG1 FA vs FTC; (B) NTHL1 FA vs FTC; (C) MUTYH FA vs FTC and (D) OGG1 NT vs FTC. 
Table 2 Year of collection, patient's gender and age and TNM staging are directly correlated with the respective gene expression level of OGG1, NTHL1 and MUTYH (normalised for the housekeeping gene $A C T B$ ) of 25 FTCs investigated as fresh frozen specimen in the study

\begin{tabular}{|c|c|c|c|c|c|c|}
\hline No. ${ }^{a}$ & Year & $\begin{array}{l}\text { Age, } \\
\text { gender }\end{array}$ & TNM & $\begin{array}{c}\text { OG- } \\
\text { G1I } \\
\text { ACTB }\end{array}$ & $\begin{array}{c}\text { NTH- } \\
\text { L1/ } \\
\text { ACTB }\end{array}$ & $\begin{array}{c}\text { MUTYHI } \\
\text { ACTB }\end{array}$ \\
\hline 1 & 1996 & $68, F$ & рT3 Nx Mx & 0.26 & 0.88 & 0.45 \\
\hline 2 & 1996 & $72, \mathrm{M}$ & рT3 Nx Mx & 0.41 & 1.29 & 0.31 \\
\hline 3 & 1996 & $60, \mathrm{~F}$ & pT4 Nx M1 & 0.44 & $1 \cdot 16$ & 0.37 \\
\hline 4 & 1999 & $60, \mathrm{~F}$ & pT4 pNO Mx & 0.35 & 0.91 & 0.23 \\
\hline 5 & 1999 & $41, F$ & pT4b N1 M0 & 0.78 & 0.59 & 0.61 \\
\hline 6 & 1999 & $35, \mathrm{~F}$ & pT4 pNO MO & 0.38 & $1 \cdot 66$ & 0.9 \\
\hline 7 & 2000 & $61, M$ & pT4 Nx Mx & 0.32 & 1.03 & 0.86 \\
\hline 8 & 2000 & $64, \mathrm{~F}$ & pT4b pN1b Mx & 0.56 & 4.92 & 0.78 \\
\hline 9 & 2001 & $75, \mathrm{M}$ & рT3 pN1 Mx & 0.27 & 0.65 & 0.81 \\
\hline 10 & 2001 & $59, M$ & рT3 Nx MO & $1 \cdot 15$ & 0.78 & 0.32 \\
\hline 11 & 2001 & $77, \mathrm{~F}$ & рT3 pNO Mx & 1.23 & 1.54 & $1 \cdot 16$ \\
\hline 12 & 2001 & $59, M$ & pT3 pNx pM1pul & 0.69 & 0.97 & 0.45 \\
\hline 13 & 2002 & $54, \mathrm{~F}$ & рT2a pNo pMx & $2 \cdot 19$ & $10 \cdot 48$ & $9 \cdot 38$ \\
\hline 14 & 2002 & $76, \mathrm{~F}$ & pT2 pNx pMx & 0.43 & 0.52 & 0.2 \\
\hline 15 & 2002 & $71, \mathrm{~F}$ & pT4 pNO Mx & 0.21 & 0.27 & 0.08 \\
\hline 16 & 2002 & $82, \mathrm{~F}$ & pT4 pN0 M1 & $1 \cdot 42$ & 1.92 & 0.93 \\
\hline 17 & 2003 & $50, M$ & pT3 pNO MO & 0.33 & $1 \cdot 13$ & 0.59 \\
\hline 18 & 2003 & $69, \mathrm{~F}$ & pT4b pNx Mx & 0.32 & 0.19 & $0 \cdot 13$ \\
\hline 19 & 2003 & $71, \mathrm{~F}$ & pT4b pNO Mx & 2.57 & $1 \cdot 34$ & 1.4 \\
\hline 20 & 2003 & $71, \mathrm{~F}$ & pT4b N1b M1c & $5 \cdot 28$ & 0.53 & 0.52 \\
\hline 21 & 2003 & $72, \mathrm{~F}$ & pT4 pNx Mx & 0.54 & 0.34 & 0.18 \\
\hline 22 & 2003 & $74, \mathrm{~F}$ & рТ3 Nx Mx & 0.31 & 0.35 & $0 \cdot 13$ \\
\hline 23 & 2004 & $50, \mathrm{~F}$ & pT2 pN0 pM1oss & $0 \cdot 61$ & $1 \cdot 65$ & 0.56 \\
\hline 24 & 2004 & $83, \mathrm{~F}$ & pT2 pN0 pM1oss & $0 \cdot 17$ & 0.97 & 0.92 \\
\hline 25 & 2004 & $58, \mathrm{~F}$ & pT2 pNo Mx & 0.25 & 0.73 & 0.67 \\
\hline
\end{tabular}

${ }^{\mathrm{a}}$ No. in tissue bank.

As oxidative DNA damage may be due to i) increased oxidative stress and/or ii) impaired DNA repair, the gene expression of DNA damage repair enzymes $O G G 1$, MUTYH and NTHL1 was studied. Interestingly, all three BER genes were significantly downregulated in FTC but were upregulated in FA compared with NT.

To investigate whether these changes indeed reflect DNA damage response, we exposed FTRL-5 cells to u.v. irradiation, which is an established mode for induction of oxidative stress (Driessens et al. 2009). U.v. irradiation resulted in increased activation of H2AFX and was accompanied by mRNA downregulation of the DNA damage repair genes $O g g 1$, Mutyh and Nthl1 in FRTL-5 cells. Thus, these findings mirror the in vivo picture in FTC, which likewise display activation of cell cycle checkpoints in contrast to follicular adenoma (Krause et al. 2011). However, in FRTL-5 cells, the u.v.-induced changes were temporary, reflecting the physiological response in a 'healthy' system, while changes in FTC are not. This is in line with FTC representing a 'diseased' system hallmarked by constitutive activation of specific signal transduction (Fagin 2002, Kondo et al. 2006) promoting, e.g. oxidative stress and/or impairing DNA repair.
During analysis of our FTC samples, we noted differences in the extent of 8-OxoG formation depending on their morphological appearance. In a subsequent analysis, we addressed this issue more specifically for the two FTC variants (oxyphilic and non-oxyphilic) under study. Oxyphilic follicular carcinomas are largely composed of oncocytic cells ( $>75 \%$ of the tumour cells according to WHO criteria), which contain large masses of mitochondria and are genetically characterised by mitochondrial DNA mutations in contrast to non-oxyphilic FTC, which display constitutive activation of PI3K activation ( $\mathrm{Hu}$ et al. 2008, Gasparre et al. 2010). Two interesting pictures emerged in our subset analysis. First, oxyphilic FTC displayed significantly lower nuclear and cytosolic 8-OxoG

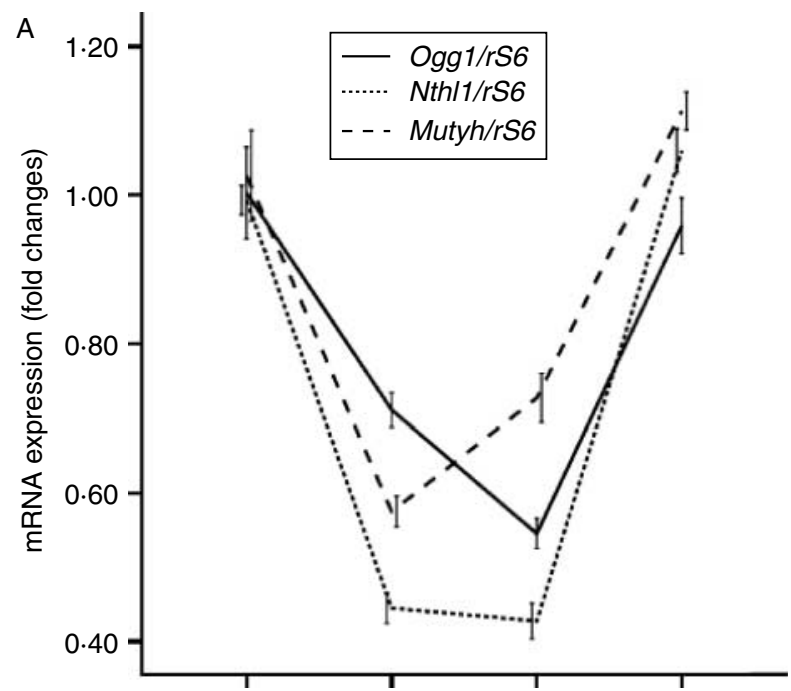

B

WB anti:

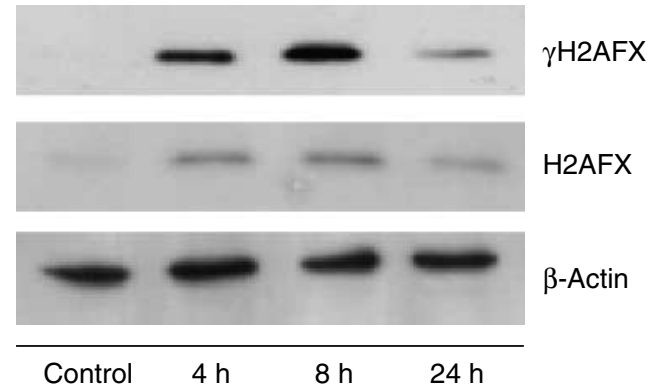

Figure 4 (A) Changes in mRNA expression of the DNA base excision repair enzymes Ogg1, Nthl1, and Mutyh in FRTL- 5 cells $4 \mathrm{~h}$ (Nthl1: $P<0.017$; Mutyh $P<0.025), 8 \mathrm{~h}($ Ogg1 $P<0.025)$ and $24 \mathrm{~h}$ after u.v. irradiation compared with non-irradiated cells. Gene expression was normalised for $r S 6$ mRNA expression and was determined by real-time PCR as described in the Materials and methods section. (B) Expression and activation (phosphorylation) of the cell cycle checkpoint regulator H2AFX upon u.v. irradiation (single dose of $0.001 \mathrm{~J} / \mathrm{cm}^{2}$ ) in FRTL-5 cells as investigated by western blot analysis. $\beta$-Actin was used as a loading control. Both experiments $(A)$ and $(B)$ were performed in triplicates. 
A

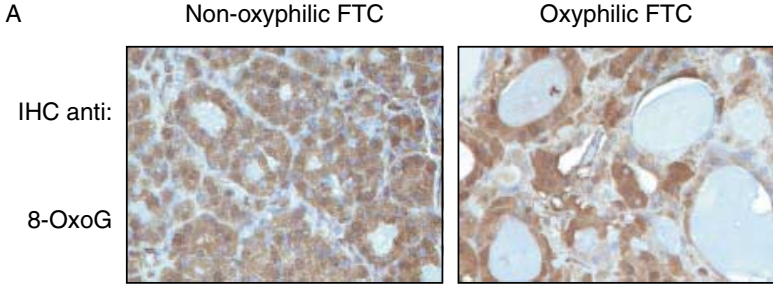

B

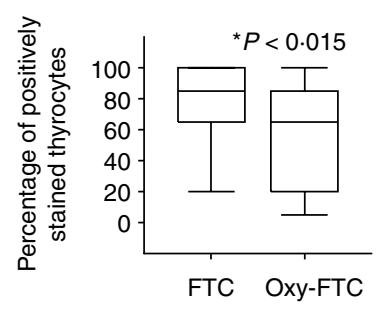

Nuclear

C

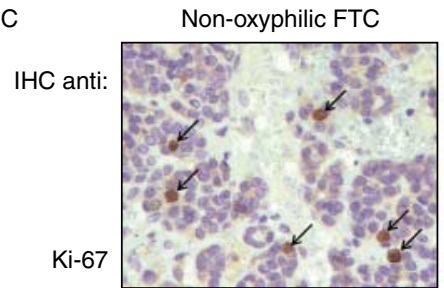

Figure 5 (A) Representative images of 8-OxoG immunoreactivity in non-oxyphilic FTC and oxyphilic FTC, which are characterised by their larger mitochondrial content and represent a frequent FTC variant. Magnification: $400 \times$. (B) Box plots show median and distribution (box area $=50 \%$ of samples) of the percentage of 8-OxoG positively stained thyrocytes (nuclear and cytosolic) in non-oxyphilic FTC and oxyphilic FTC. The mean nuclear 8-OxoG staining was $75.4 \pm 30.7 \%$ in non-oxyphilic FTC (median $85 \%$ ) and $53.5 \pm 31.8 \%$ in oxyphilic FTC (median $65 \%$ ). This difference was calculated as significant $\left({ }^{*} P<0.015\right.$; Mann-Whitney $U$ test). The mean cytosolic 8-OxoG staining in non-oxyphilic FTC was $85 \cdot 4 \pm 24.6 \%$ (median $100 \%$ ) and in oxyphilic FTC $77 \cdot 4 \pm 30 \cdot 3 \%$ (median 85\%). (C) Ki-67 labelling index in non-oxyphilic FTC and oxyphilic FTC showed a higher rate of cellular proliferation reflected by a higher percentage of MIB-1-positive nuclei (arrows) in non-oxyphilic FTC (median $2.1 \%$ ) vs oxyphilic FTC (median $1 \cdot 0 \%$ ). Magnification: $400 \times$. Full colour version of this figure available via http://dx.doi.org/10.1530/JME-11-0119.

staining than non-oxyphilic FTC. Second, activation of DNA damage response markers was more pronounced in oxyphilic compared with non-oxyphilic FTC, whereby the cytosolic finding of activated ATM and H2AFX in oxyphilic FTC most likely reflects mitochondrial DNA alterations in line with the characteristic finding of mtDNA mutations (Gasparre et al. 2010). However, the differences in nuclear 8-OxoG formation and nuclear DNA damage response between the two FTC variants could argue for preservation of a more sustained cell cycle control in oxyphilic FTC, whereby checkpoint activation allows repair of oxidative DNA damage resulting in a lower degree of persistent
DNA damage. As these studies were performed on archival paraffin-embedded tissues, we were not able to study mRNA expression of DNA repair genes. However, our rationale is substantiated by the finding of a much lower (but below statistical significance) proliferation rate in oxyphilic compared with non-oxyphilic FTC, which has also been previously described by other investigators (Vonate et al. 2002).

Though the biological behaviour of oxyphilic tumours is still debated, our findings of increased (nuclear) checkpoint activation, decreased proliferation and decreased (nuclear) oxidative damage in oxyphilic FTC would suggest a more benign course of disease.

Very recent evidence for this reasoning comes from a study by Porcelli et al. (2010) who showed that the occurrence of disruptive mitochondrial DNA mutations mostly in respiratory complex I, which are the genetic hallmarks of oncocytic cell transformation, contribute to contain the tumour in a benign state by inhibiting stabilisation of the hypoxia-inducible factor $1 \alpha$.

We believe that clinical studies addressing this issue more specifically are required and are mandatory to interpret the success of yet experimental therapies, e.g. with tyrosine kinase inhibitors or other drugs targeting oxidative stress response in patients with different FTC variants.

In summary, we provide the first evidence that increased oxidative stress and stress-induced DNA damage are the hallmarks of follicular thyroid tumours with downregulation of the DNA repair machinery in FTC vs upregulation in benign FA. Furthermore, we demonstrate that oxidative damage is more pronounced in non-oxyphilic compared with oxyphilic FTC. In our view, this finding merits further investigation as to its biological outcome and clinical relevance.

\section{Supplementary data}

This is linked to the online version of the paper at http://dx.doi.org/ 10.10.1530/JME-11-0119.

\section{Declaration of interest}

The authors declare that there is no conflict of interest that could be perceived as prejudicing the impartiality of the research reported.

\section{Funding}

This study was supported by the Deutsche Forschungsgemeinschaft (DFG grant FU 356/3-1) and a formel.1 grant (SK 934000-363) of the Faculty of Medicine, University of Leipzig. 


\section{Author contribution statement}

$\mathrm{S} \mathrm{K}$ and $\mathrm{K} \mathrm{K}$ planned and carried out the experiments, $\mathrm{C} \mathrm{E}$ and $\mathrm{C} \mathrm{W}$ helped with experiments and analysed data. O G and H D were the surgeons who removed the thyroid tumours; S-Y, S-G and K W S were the pathologists who carried out histological classification of the thyroid tumours. D F planned the experiments and supervised all the work on this paper. All authors were involved in writing the paper and had final approval of the submitted and published versions.

\section{Acknowledgement}

The authors are grateful to Monika Gutknecht for excellent technical assistance and to Dr Anke Tönjes for her advice with statistical analysis.

\section{References}

Al-Tassan N, Chmiel NH, Maynard J, Fleming N, Livingston AL, Williams GT, Hodges AK, Davies DR, David SS, Sampson JR et al. 2002 Inherited variants of MYH associated with somatic G:C $\rightarrow$ T:A mutations in colorectal tumors. Nature Genetics 30 227-232. (doi:10.1038/ng828)

van Attikum H \& Gasser SM 2009 Crosstalk between histone modifications during the DNA damage response. Trends in Cell Biology 19 207-217. (doi:10.1016/j.tcb.2009.03.001)

Bartkova J, Horejsi Z, Koed K, Krämer A, Tort F, Zieger K, Guldberg P, Sehested M, Nesland JM, Lukas C et al. 2005 DNA damage response as a candidate anti cancer barrier in early human tumorigenesis. Nature 434 864-870. (doi:10.1038/nature03482)

Beckmann KB \& Ames BN 1997 Oxidative decay of DNA. Journal of Biological Chemistry 272 19633-19636. (doi:10.1074/jbc.272.32. 19633)

Carlini M, Giovannini C, Castaldi F, Mercadante E, Dell'Avanzato R, Zazza S, Nania A, Santeusanio G, Passeri M \& Di Perna P 2005 High risk for micro carcinoma in thyroid benign diseases. Incidence in a one year period of total thyroidectomies. Journal of Experimental $\mathcal{E}^{\circ}$ Clinical Cancer Research 24 231-236.

Dal Maso L, Lise M, Zambon P, Falcini F, Crocetti E, Serraino D, Cirilli C, Zanetti R, Vercelli M, Ferretti S et al. \& for AIRTUM Working Group 2011 Incidence of thyroid cancer in Italy, 19912005: time trend and age-period-cohort effects. Annals of Oncology 22 957-963. (doi:10.1093/annonc/mdq467)

David SS, O'Shea VL \& Kundu S 2007 Base-excision repair of oxidative DNA damage. Nature 447 941-950. (doi:10.1038/nature05978)

De Deken X, Wang D, Dumont JE \& Miot F 2002 Characterization of ThOX proteins as components of the thyroid $\mathrm{H}(2) \mathrm{O}(2)$-generating system. Experimental Cell Research 15 187-196. (doi:10.1006/excr. 2001.5444)

Driessens N, Versteyhe S, Ghaddhab C, Burniat A, De Deken X, Van Sande J, Dumont JE, Miot F \& Corvilain B 2009 Hydrogen peroxide induces DNA single- and double-strand breaks in thyroid cells and is therefore a potential mutagen for this organ. EndocrineRelated Cancer 16 845-856. (doi:10.1677/ERC-09-0020)

Fagin JA 2002 Minireview: branded from the start-distinct oncogenic initiating events may determine tumor fate in the thyroid. Molecular Endocrinolgy 16 903-911. (doi:10.1210/me.16.5.903)

Gasparre G, Bonora E, Tallini G \& Romeo G 2010 Molecular features of thyroid oncocytic tumors. Molecular and Cellular Endocrinology 28 67-76. (doi:10.1016/j.mce.2010.02.022)

Hoeijmakers JH 2009 DNA damage, aging, and cancer. New England Journal of Medicine 361 1475-1485. (doi:10.1056/NEJMra0804615)

Hu J, Xia X, Cheng A, Wang G, Luo X, Reed MF, Fojo T, Oetting A, Gong J \& Yen PM 2008 A peptide inhibitor derived from p55PIK phosphatidylinositol 3-kinase regulatory subunit: a novel cancer therapy. Molecular Cancer Therapeutics 7 3719-3728. (doi:10.1158/ 1535-7163.MCT-08-0499)

Husmann G, Kaatsch P, Katalinic A, Bertz J, Haberland J, Kraywinkel K \& Wolf U 2010 Cancer in Germany 2005/2006. Incidence and trends. 7th edn. Eds Robert Koch Institute and Association of Population-based Cancer Registries in Germany. Berlin.

Jackson SP \& Bartek J 2009 The DNA-damage response in human biology and disease. Nature 461 1071-1078. (doi:10.1038/ nature08467)

Karger S, Weidinger C, Krause K, Sheu SY, Aigner T, Gimm O, Schmid KW, Dralle H \& Fuhrer D 2009 FOXO3a: a novel player in thyroid carcinogenesis? Endocrine-Related Cancer 16 189-199. (doi:10.1677/ERC-07-0283)

Klungland A, Rosewell I, Hollenbach S, Larsen E, Daly G, Epe B, Seeberg E, Lindahl T \& Barnes DE 1999 Accumulation of premutagenic DNA lesions in mice defective in removal of oxidative base damage. PNAS 96 13300-13305. (doi:10.1073/pnas.96. 23.13300)

Köhrle J, Jakob F, Contempre B \& Dumont JE 2005 Selenium, the thyroid, and the endocrine system. Endocrine Reviews 26 944-984. (doi:10.1210/er.2001-0034)

Kondo T, Ezzat S \& Asa SL 2006 Pathogenetic mechanisms in thyroid follicular-cell neoplasia. Nature Reviews. Cancer 6 292-306. (doi:10.1038/nrc1836)

Kong Q \& Lin CL 2010 Oxidative damage to RNA: mechanisms, consequences, and diseases. Cellular and Molecular Life Sciences 67 1817-1829. (doi:10.1007/s00018-010-0277-y)

Krause K, Karger S, Schierhorn A, Poncin S, Many MC \& Fuhrer D 2007 Proteomic profiling of cold thyroid nodules. Endocrinology 148 1754-1763. (doi:10.1210/en.2006-0752)

Krause K, Eszlinger M, Gimm O, Karger S, Engelhardt C, Dralle H \& Fuhrer D 2008 TFF3-based candidate gene discrimination of benign and malignant thyroid tumors in a region with borderline iodine deficiency. Journal of Clinical Endocrinology and Metabolism 93 1390-1393. (doi:10.1210/jc.2006-1255)

Krause K, Prawitt S, Eszlinger M, Ihling C, Sinz A, Schierle K, Gimm O, Dralle H, Steinert F, Sheu SY et al. 2011 Dissecting molecular events in thyroid neoplasia provides evidence for distinct evolution of follicular thyroid adenoma and carcinoma. American Journal of Pathology 179 3066-3074. (doi:10.1016/j.ajpath. 2011.08.033)

Kreutzer DA \& Essigmann JM 1998 Oxidized, deaminated cytosines are a source of $\mathrm{C} \rightarrow \mathrm{T}$ transitions in vivo. PNAS 95 3578-3582. (doi:10.1073/pnas.95.7.3578)

Krohn K, Führer D, Bayer Y, Eszlinger M, Brauer V, Neumann S \& Paschke R 2005 Molecular pathogenesis of euthyroid and toxic multinodular goiter. Endocrine Reviews 26 504-524. (doi:10.1210/er. 2004-0005)

Liu S, Semenciw R, Ugnat AM \& Mao Y 2001 Increasing thyroid cancer incidence in Canada, 1970-1996: time trends and age-periodcohort effects. British Journal of Cancer 85 1335-1339. (doi:10.1054/ bjoc.2001.2061)

van Loon B, Markkanen E \& Hübscher U 2010 Oxygen as a friend and enemy: how to combat the mutational potential of 8-oxo-guanine. DNA Repair 9 604-616. (doi:10.1016/j.dnarep.2010.03.004)

Maier J, van Steeg H, van Oostrom C, Karger S, Paschke R \& Krohn K 2006 Deoxyribonucleic acid damage and spontaneous mutagenesis in the thyroid gland of rats and mice. Endocrinology 147 3391-3397. (doi:10.1210/en.2005-1669)

Minowa O, Arai T, Hirano M, Monden Y, Nakai S, Fukuda M, Itoh M, Takano H, Hippou Y, Aburatani H et al. 2000 $\mathrm{Mmh} / \mathrm{Oggl}$ gene inactivation results in accumulation of 8-hydroxyguanine in mice. PNAS 97 4156-4161. (doi:10.1073/ pnas.050404497)

Pfaffl MW 2001 A new mathematical model for relative quantification in real-time RT-PCR. Nucleic Acids Research 29 e45. (doi:10.1093/ nar/29.9.e45) 
Porcelli AM, Ghelli A, Ceccarelli C, Lang M, Cenacchi G, Capristo M, Pennisi LF, Morra I, Ciccarelli E, Melcarne A et al. 2010 The genetic and metabolic signature of oncocytic transformation implicates HIFla destabilisation. Human Molecular Genetics 19 1019-1032. (doi:10.1093/hmg/ddp566)

Rosenquist TA, Zharkov DO \& Grollman AP 1997 Cloning and characterization of a mammalian 8-oxoguanine DNA glycosylase. PNAS 94 7429-7434. (doi:10.1073/pnas.94.14.7429)

Russo MT, De Luca G, Degan P \& Bignami M 2007 Different DNA repair strategies to combat the threat from 8-oxoguanine. Mutation Research 614 69-76. (doi:10.1016/j.mrfmmm.2006.03.007)

Song Y, Driessens N, Costa M, De Deken X, Detours V, Corvilain B, Maenhaut C, Miot F, Van Sande J, Many M-C et al. 2007 Roles of hydrogen peroxide in thyroid physiology and disease. Journal of Clinical Endocrinology and Metabolism 92 3764-3773. (doi:10.1210/jc. 2007-0660)

Song Y, Ruf J, Lothaire P, Dequanter D, Andry G, Willemse E, Dumont JE, Van Sande J \& De Deken X 2010 Association of duoxes with thyroid peroxidise and its regulation in thyrocytes. Journal of Clinical Endocrinology and Metabolism 95 375-382. (doi:10.1210/jc. 2009-1727)
Shattuck TM, Westra WH, Ladenson PW \& Arnold A 2005 Independent clonal origins of distinct tumor foci in multifocal papillary thyroid carcinoma. New England Journal of Medicine 352 2406-2412. (doi:10.1056/NEJMoa044190)

Tanaka T, Huang X, Jorgensen E, Gietl D, Traganos F, Darzynkiewicz Z \& Albino AA 2007 ATM activation accompanies histone H2AX phosphorylation in A549 cells upon exposure to tobacco smoke. BMC Cell Biology 8 26. (doi:10.1186/1471-2121-8-26)

Volzke H, Ludemann J, Robinson DM, Spieker KW, Schwahn C, Kramer A, John U \& Meng W 2003 The prevalence of undiagnosed thyroid disorders in a previously iodine-deficient area. Thyroid 13 803-810. (doi:10.1089/105072503768499680)

Vonate M, Croce S, Pecchioni C \& Papotti M 2002 E2F-1 transcription factor is overexpressed in oxyphilic thyroid tumours. Modern Pathology 15 1038-1043. (doi:10.1097/01.MP.0000028645. 36632.A8)

Received in final form 4 January 2012 Accepted 10 February 2012

Made available online as an Accepted Preprint 10 February 2012 